\title{
Association between pregnancy-induced hypertension and asthma during pregnancy
}

\author{
Steven Lehrer, MD, ${ }^{a}$ Joanne Stone, MD, ${ }^{b}$ Robert Lapinski, PhD, ${ }^{b}$ Charles J. Lockwood, MD, \\ Beth S. Schachter, PhD, ${ }^{b}$ Richard Berkowitz, MD, ${ }^{b}$ and Gertrud S. Berkowitz, PhD \\ New York, New York
}

OBJECTIVE: Pregnancy-induced hypertension is an important cause of maternal mortality, intrauterine growth retardation, and perinatal mortality. We examined the relationship between pregnancy-induced hypertension and asthma.

STUDY DESIGN: The study population consisted of 24,115 women without a history of chronic systemic hypertension who were delivered of live born and stillborn infants at Mount Sinai Medical Center between January 1987 and December 1991. Pregnancy-induced hypertension was defined as blood pressure of at least $140 / 90 \mathrm{~mm} \mathrm{Hg}$ or an increase of $\geq 30 \mathrm{~mm} \mathrm{Hg}$ in systolic pressure or $\geq 15 \mathrm{~mm} \mathrm{Hg}$ in diastolic pressure.

RESULTS: There was a significant association between pregnancy-induced hypertension and asthma during pregnancy $\left(\chi^{2}=17.86, p<0.001\right)$. In addition, there was a significant upward trend in the incidence of asthma during pregnancy in women without, with moderate, and with severe pregnancy-induced hypertension (Mantel-Haenszel $\chi^{2}=11.8, p=0.001$ ). Logistic regression analysis demonstrated that the association between pregnancy-induced hypertension and asthma during pregnancy persisted after adjustment for the confounding factors of race or ethnicity, maternal age, parity, and prepregnancy weight (adjusted odds ratio $2.52,95 \%$ confidence interval 1.47 to $4.35, p=0.0008$ ). An association between pregnancy-induced hypertension and a history of asthma was also found $\left(x^{2}=11.2, p=0.001\right)$. However, after adjustment for potential confounders, this association failed to achieve statistical significance (adjusted odds ratio $1.2,95 \%$ confidence interval 0.97 to $1.53, p=0.083$ ). CONCLUSION: Both pregnancy-induced hypertension and asthma might be caused by a third factor affecting smooth muscle reactivity. (AM J OBSTET GYNECOL 1993;168:1463-6.)

Key words: Pregnancy-induced hypertension, asthma

Pregnancy-induced hypertension is a major cause of maternal mortality, intrauterine growth retardation, and perinatal mortality. ${ }^{1,2}$ Pregnancy-induced hypertension is also an important component of preeclampsia, a disorder of pregnancy characterized by hypertension, proteinuria, edema, and at times thrombocytopenia and disturbances of liver function. ${ }^{3}$ We report here that asthma during pregnancy may be a risk factor for pregnancy-induced hypertension.

\section{Methods}

The study population consisted of 24,115 women without a history of chronic systemic hypertension who were delivered of live born and stillborn infants at Mount Sinai Medical Center between January 1987 and

From the Departments of Radiation Oncology and Obstetrics, Gynecology, and Reproductive Science, ${ }^{b}$ Mount Sinai School of Medicine. Supported by National Institutes of Health grant No. HD 27557 and by a grant from the Edgar McCoubrey Foundation.

Received for publication July 26, 1992; revised November 3, 1992; accepted November 16, 1992.

Reprint requests: Steven Lehrer, MD, Radiation Oncology, Box

1236, Mount Sinai Medical Center, New York, NY 10029.

Copyright (1) 1993 by Mosby-Year Book, Inc.

$0002-9378 / 93 \$ 1.00+.206 / 1 / 44285$
December 1991. The data were obtained from a computerized perinatal data base that includes detailed information on all patients who delivered at Mount Sinai Medical Center. The accuracy of data entry is periodically confirmed by reviewing selected patient records.

Asthma during pregnancy was defined as asthma that necessitated treatment. Pregnancy-induced hypertension was defined as blood pressure of at least 140/90 $\mathrm{mm} \mathrm{Hg}$ or an increase of $\geq 30 \mathrm{~mm} \mathrm{Hg}$ in systolic pressure or $\geq 15 \mathrm{~mm} \mathrm{Hg}$ in diastolic pressure. Pregnancy-induced hypertension was classified as moderate if systolic blood pressure fell into the range of 140 to $160 \mathrm{~mm} \mathrm{Hg}$ and diastolic blood pressure was 90 to 110 $\mathrm{mm} \mathrm{Hg}$. Pregnancy-induced hypertension was classified as severe if systolic pressure was $>160 \mathrm{~mm} \mathrm{Hg}$ or diastolic pressure was $>110 \mathrm{~mm} \mathrm{Hg}$. Chronically hypertensive patients, that is, patients hypertensive before they became pregnant, were excluded from the analysis.

In addition to pregnancy-induced hypertension the variables assessed included maternal age, parity, race, prepregnancy weight, presence of gestational diabetes, history of asthma, and asthma during pregnancy. Be- 


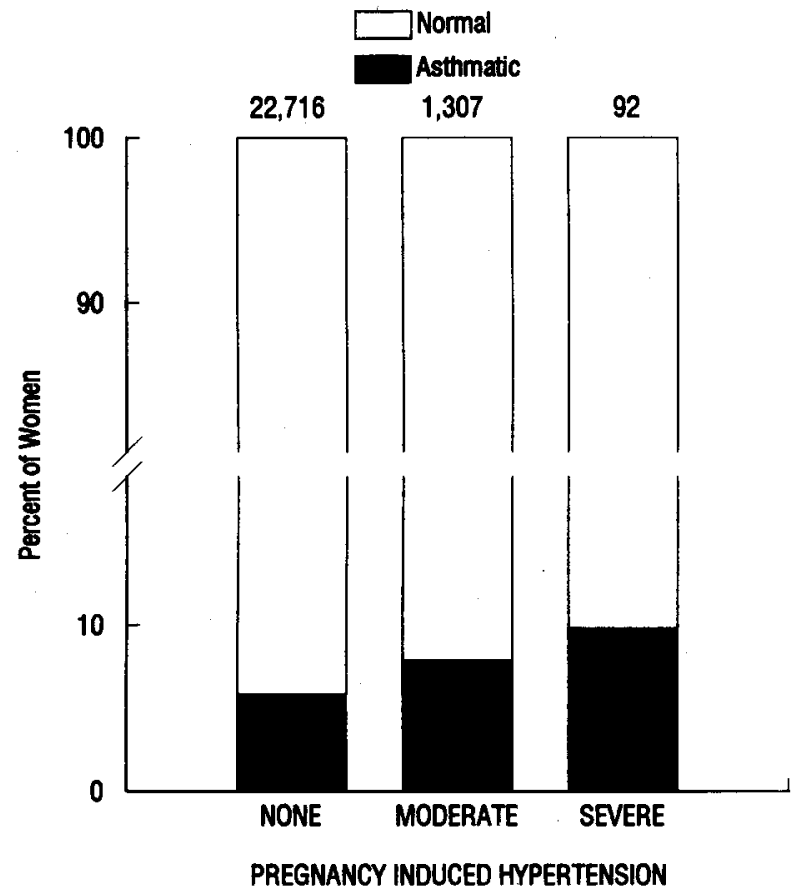

Fig. 1. Asthma during pregnancy and pregnancy-induced hypertension in women in this study. Number of cases in each group is indicated above corresponding bar.

cause black or Hispanic women might be at increased risk of pregnancy-induced hypertension and because these same women might also have increased risk of asthma, the influence of race or ethnicity and other potential confounders was controlled for by logistic regression analysis. Odds ratios, which approximate relative risks, were calculated for pregnancy-induced hypertension and for the other variables listed above. SEs were used to determine $95 \%$ confidence intervals. All statistical analyses were performed with the SAS system. ${ }^{4}$

\section{Results}

Of the 24,115 women studied, 1307 had moderate pregnancy-induced hypertension, and 92 had severe pregnancy-induced hypertension. Of the total number of women, 1435 had a history of asthma and 136 had asthma during pregnancy.

There was a significant association between pregnancy-induced hypertension and asthma during pregnancy $\left(x^{2}=16.7, p<0.001\right)$. In addition, there was a significant upward trend in the incidence of asthma during pregnancy in women with no pregnancy-induced hypertension, moderate pregnancy-induced hypertension, and severe pregnancy-induced hypertension (Mantel-Haenszel $\chi^{2}=11.8, p=0.001$, Fig. 1).

Analysis by logistic regression demonstrated that women with asthma during pregnancy were significantly more likely to have pregnancy-induced hyperten- sion (adjusted odds ratio $2.52,95 \%$ confidence interval 1.47 to $4.35, p=0.0008$ ). This association was independent of the effects of the other independent variables: race, maternal age, parity, and prepregnancy weight (Table I).

Because the data for this study were derived from a computerized data bank, the occurrence of asthma might be underreported. However, one would expect equal underreporting of pregnancy-induced hypertension.

An association between pregnancy-induced hypertension and a history of asthma was also found $\left(\chi^{2}=11.2\right.$, $p=0.001)$. However, after adjustment for potential confounders, this association failed to achieve statistical significance (adjusted odds ratio 1.2, 95\% confidence interval 0.97 to $1.53, p=0.083$, Table II). There was no association between asthma during pregnancy and gestational diabetes $\left(\chi^{2}=0.85, p=0.355\right)$.

\section{Comment}

Pregnancy-induced hypertension and preeclampsia are closely related, and various factors predispose to preeclampsia: nulliparity, ${ }^{5}$ history of preeclampsia in a multiparous woman, ${ }^{6}$ black race, ${ }^{7}$ high body mass, ${ }^{1}$ family history of hypertension, ${ }^{1}$ and advanced maternal age. ${ }^{1}$ Only cigarette smoking is protective. ${ }^{8,9}$ The data presented above indicate that some of these factors also predispose to pregnancy-induced hypertension.

There are at least three possible explanations for the association of pregnancy-induced hypertension and asthma during pregnancy. One is that the medicines used to treat the asthma, specifically glucocorticoids, might cause the pregnancy-induced hypertension. However, only aerosol glucocorticoids were used in the pregnant asthmatics we studied. Administered in this form, the glucocorticoid side effects are minimal.

Also, glucocorticoids increase the risk of gestational diabetes. Because there was no correlation between gestational diabetes and asthma during pregnancy in our study, glucocorticoid use is unlikely to be a confounding variable. In addition, a study of 85 corticosteroid-dependent patients with respiratory disease showed that the prevalence of hypertension was not greater in these patients than in the general population. ${ }^{10}$

One wonders whether any women with pregnancyinduced hypertension were treated with aspirin. Aspirin might then be a confounding variable because of aspirin-induced asthma. However, use of aspirin during pregnancy in our patients was extremely rare. It was used as an anticoagulant in women with lupus, but these women were excluded from our study.

A second possible explanation for the association of pregnancy-induced hypertension and asthma during pregnancy is that the stress of the hypertension brings 
Table I. Association of pregnancy-induced hypertension and asthma during pregnancy, controlling for maternal age, parity, race or ethnicity, and prepregnancy weight

\begin{tabular}{|c|c|c|c|}
\hline & Adjusted odds ratio & $95 \%$ Confidence interval & Significance \\
\hline Asthma during pregnancy & 2.52 & $1.47-4.35$ & $p=0.0008$ \\
\hline Maternal age (yr)* & 1.03 & $1.02-1.04$ & $p=0.0001$ \\
\hline Parity $\dagger$ & 0.78 & $0.73-0.83$ & $p=0.0001$ \\
\hline Race + & 1.58 & $1.37-1.83$ & $p=0.0001$ \\
\hline Prepregnancy weight§ & 1.018 & $1.016-1.020$ & $p=0.0001$ \\
\hline
\end{tabular}

*Increase in risk per year.

†Decrease in risk per birth.

$\ddagger$ Increase in risk for black or Hispanic versus others.

$\S$ Increase in risk per pound.

Table II. Association of pregnancy-induced hypertension and history of asthma, controlling for maternal age, parity, race or ethnicity, and prepregnancy weight

\begin{tabular}{|c|c|c|c|}
\hline & Adjusted odds ratio & $95 \%$ Confidence interval & Significance \\
\hline History of asthma & 1.2 & $0.97-1.53$ & $p=0.083$ \\
\hline Maternal age* & 1.03 & $1.01-1.04$ & $p=0.0001$ \\
\hline Parity† & 0.78 & $0.73-0.83$ & $p=0.0001$ \\
\hline Racef & 1.57 & $1.35-1.81$ & $p=0.0001$ \\
\hline Prepregnancy weight§ & 1.02 & $1.01-1.02$ & $p=0.0001$ \\
\hline
\end{tabular}

*Increase in risk per year.

$\dagger$ Decrease in risk per birth.

$¥$ Increase in risk for black or Hispanic versus others.

$\S$ Increase in risk per pound.

on asthma attacks, or vice versa. A third possibility is that both are caused by a circulating factor affecting smooth muscle reactivity.

The causes of the altered vascular smooth muscle reactivity associated with pregnancy-induced hypertension are unknown. One mechanism proposed is vascular endothelial cell dysfunction'; circulating substances that stimulate the production of growth factors, such as platelet-derived growth factor, have been implicated in this.dysfunction. ${ }^{11-13}$ In addition, circulating lipid peroxides, endothelin, and serotonin are under study, although the findings have not been consistent. ${ }^{1}$ Another hypothesized mechanism holds that the vasoconstriction in pregnancy-induced hypertension is the result of a relative or absolute deficiency of vasodilating prostaglandins. $^{14}$

As is pregnancy-induced hypertension, asthma is characterized by abnormal smooth muscle reactivity and constriction, although airways are involved rather than arteries. In addition, asthma is the most prevalent obstructive pulmonary disease during pregnancy. ${ }^{15,}{ }^{16}$ Twenty-nine percent of pregnant asthmatics report reduction in frequency or severity of asthma attacks during pregnancy, $22 \%$ report an increased number of attacks, and the remaining $49 \%$ report no change. ${ }^{15}$

Constriction of airway smooth muscle during asthma attacks may be caused by the local release of bioactive mediators. Among the substances implicated are platelet-activating factor, histamine, acetylcholine, kinins, adenosine, tachykinins, and leukotrienes. ${ }^{17}$ Of interest is the fact that leukotrienes are also implicated in the genesis of pregnancy-induced hypertension. ${ }^{18,} 19$

In summary, both pregnancy-induced hypertension and asthma are related to circulating substances that cause altered reactivity and constriction of smooth muscle. Of these substances, the leukotrienes are implicated in both conditions. Therefore it would be worthwhile to study further in women with pregnancy-induced hypertension these and perhaps other circulating bioactive mediators related to asthma. Also, the circulating factors associated with pregnancy-induced hypertension should be studied in asthmatics. Identification of the substances involved in both conditions could lead to a better understanding of the underlying mechanisms and to improved methods of treatment.

\section{REFERENCES}

1. Eskenazi B, Fenster L, Sidney S. A multivariate analysis of risk factors for preeclampsia. JAMA 1991;266:237-41.

2. Gleicher N, Boler L, Norusis M, Del Granado A. Hypertensive diseases of pregnancy and parity. Ам J ОвSTET GYNECOL 1986;154:1044-9.

3. Cunningham FG, Lindheimer MD. Hypertension in pregnancy. N Engl J Med 1992;326:927-32.

4. SAS Institute. SAS/Stat user's guide. Release 6.03 ed. Cary, North Carolina: SAS Institute, 1988:191-282. 
5. Chelsey LC. History and epidemiology of preeclampsiaeclampsia. Clin Obstet Gynecol 1984;27:801-20.

6. Sibai BM, El-Nazer A, Gonzalez-Ruiz A. Severe preeclampsia-eclampsia in young primigravid women: subsequent pregnancy outcome and remote prognosis. AM J Obstet Gynecol 1986;155:1011-6.

7. Chesley LC, Annitto JE, Cosgrove RA.The remote prognosis of eclamptic women: sixth periodic report. AM J OBSTET GyNECOL 1976;124:446-56.

8. Marcoux S, Brisson J, Fabia J. The effect of cigarette smoking on the risk of preeclampsia and gestational hypertension. Am J Epidemiol 1989;130:950-7.

9. Palmgren B, Wahlent $T$, Wallander B. Toxemia and cigarette smoking during pregnancy. Acta Obstet Gynecol Scand 1973;52:183-5.

10. Fitzsimons R, Grammer LC, Halwig JM, Aksamit T, Patterson R. Prevalence of adverse effects in corticosteroid dependent asthmatics. N Engl Reg Allergy Proc 1988;9: 157-62.

11. Roberts JM, Taylor RM, Goldfein A. Clinical and biochemical evidence of endothelial cell dysfunction in the pregnancy syndrome preeclampsia. Am J Hypertens 1991;4: 700-8.

12. Taylor RN, Heilbron DC, Roberts JM. Growth factor activity in the blood of women in whom preeclampsia develops is elevated from early pregnancy. Ам J OвSтет GYNECOL 1990;163:1839-44.

13. Taylor RN, Musci TJ, Rodgers GM, Roberts JM. Preeclamptic sera stimulate increased platelet-derived growth factor mRNA and protein expression by cultured human endothelial cells. Am J Reprod Immunol 1991;25:105-8.

14. Walsh SW. Preeclampsia: an imbalance in placental prostacyclin and thromboxane production. AM J OBSTET GYNECOL 1985; 152:335-40.

15. Greenberger PA, Patterson R. Management of asthma during pregnancy. N Engl J Med 1985;312:897-902.

16. Pauerstein CJ. Clinical obstetrics. New York: John Wiley, 1987:771-4

17. Drazen JM. Asthma. In: Wyngaarden JB, Smith LH, Bennett JC, eds. Cecil textbook of medicine. Philadelphia: WB Saunders, 1992:381-6.

18. Mitchell MD, Koenig JM. Increased production of 15 hydroxyeicosatetraenoic acid by placentae from pregnancies complicated by pregnancy-induced hypertension. Prostaglandins Leukot Essent Fatty Acids 1991;43:61-2.

19. Biagi G, DeRosa V, Pelusi G, Scagliarini G, Sani G, Coccheri $S$. Increased placental production of leukotriene B4 in gestational hypertension. Thromb Res 1990;60:377-84 